\title{
A trial of surgery for trichiasis of the upper lid from trachoma
}

\author{
M H Reacher, M J E Huber, R Canagaratnam, A Alghassany
}

International Center for Epidemiologic and Preventive

Ophthalmology, Wilmer Institute, Baltimore, USA M H Reacher

\section{Sultan Qaboos}

University, Oman

M J E Huber

National Health

Program, Ministry of

Health, Oman

$\mathrm{R}$ Canagaratnam

Ministry of Health, Oman A Alghassany

Correspondence to:

Dr M Reacher, FRCS, Room

116, Wilmer Institute, 600

North Wolfe Street,

Baltimore, Maryland 21205,

USA

Accepted for publication 30 June 1989

Figure 1: Five operations of the upper lid for trichiasis from trachoma.
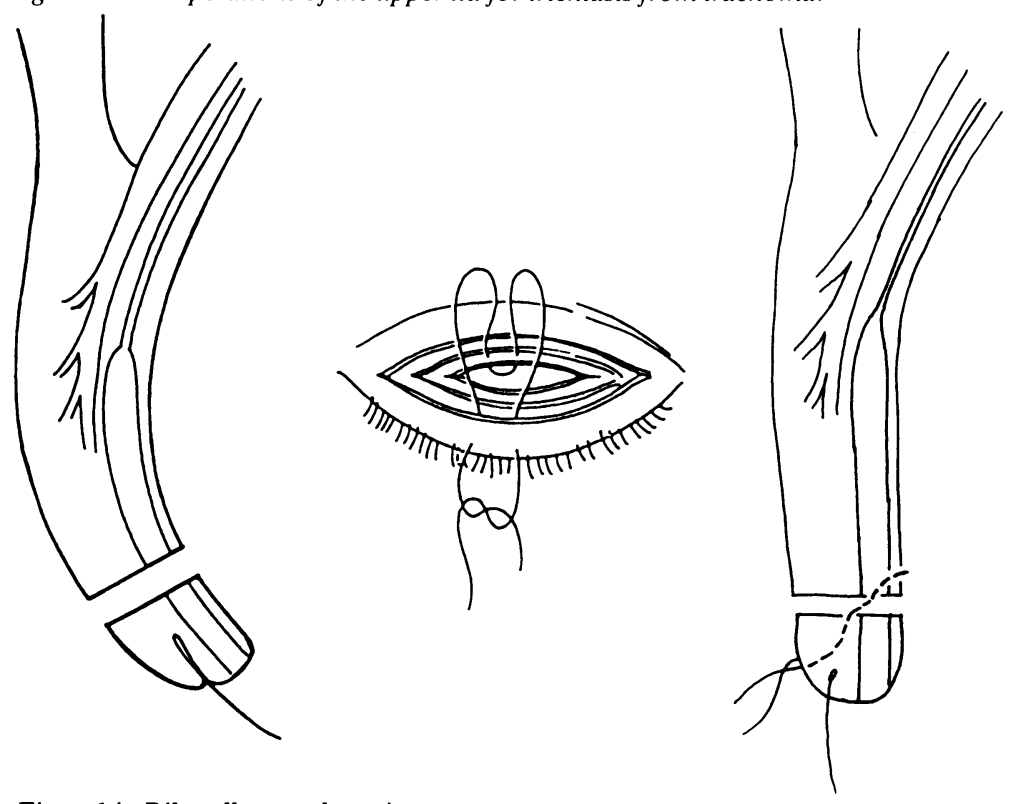

standard operations for upper lid trichiasis are few and limited in applicability to individuals from trachoma endemic communities, because most cases have causes other than trachoma ${ }^{34}$ or losses to follow-up were large. ${ }^{5}$ In order to identify effective operations for upper lid trichiasis from trachoma in rural northern Oman, where a high prevalence of potentially blinding lid deformities exist, ${ }^{6}$ a trial of standard operations was undertaken for patients brought for surgery by staff of the Oman Prevention of Blindness Programme. The programme comprises six teams of primary eye care workers. They visit villages and towns regularly, where mapping and home visits are performed prior to the preparation of a community census. Team activities include screening for inflammatory trachoma and trichiasis and compiling a list of individuals in need of lid surgery. The patients are examined at a central location, and the census list is used to ensure complete coverage. Surgery is subsequently performed at local hospitals or health centres equipped for eye lid surgery. Patients meeting our criterion of major trichiasis were commonly seen and underwent one of five operations representative of a principal type of upper lid entropion surgery. Lids with defective lid closure were less commonly seen and underwent tarsal advance.

\section{Patients and methods}

Adults diagnosed as having trichiasis by primary eye health workers and who wanted treatment were brought for eye lid surgery. Before operation a history of previous upper lid operations was obtained and an ophthalmologist examined the patient with $2 \cdot 5 \times$ loupes with eyes in the primary position, in up-gaze to view the lid margin, and closed gently as in sleep to evaluate lid closure. Upper lids were graded in the primary position as follows:

Minor trichiasis: Lid closure complete; one to five lashes in contact with eye ball.

Major trichiasis: Lid closure complete; six or more eye lashes in contact with eye ball.

Defective closure: Lid closure incomplete; any number of lashes in contact with eye ball.

The extent of trichiasis, from less than half or more than or equal to half the lid width, was also recorded. Informed consent for lid surgery was obtained. Pregnant women were excluded owing to a cultural aversion to surgery in pregnancy. Details of patients were recorded on a proforma. The operations studied were in routine use and the trial was approved by the Ministry of Health of Oman. Upper lids with major trichiasis underwent one of the following operations allocated by random number tables: bilamellar tarsal rotation ${ }^{7}$; tarsal advance and rotation ${ }^{8}$; 

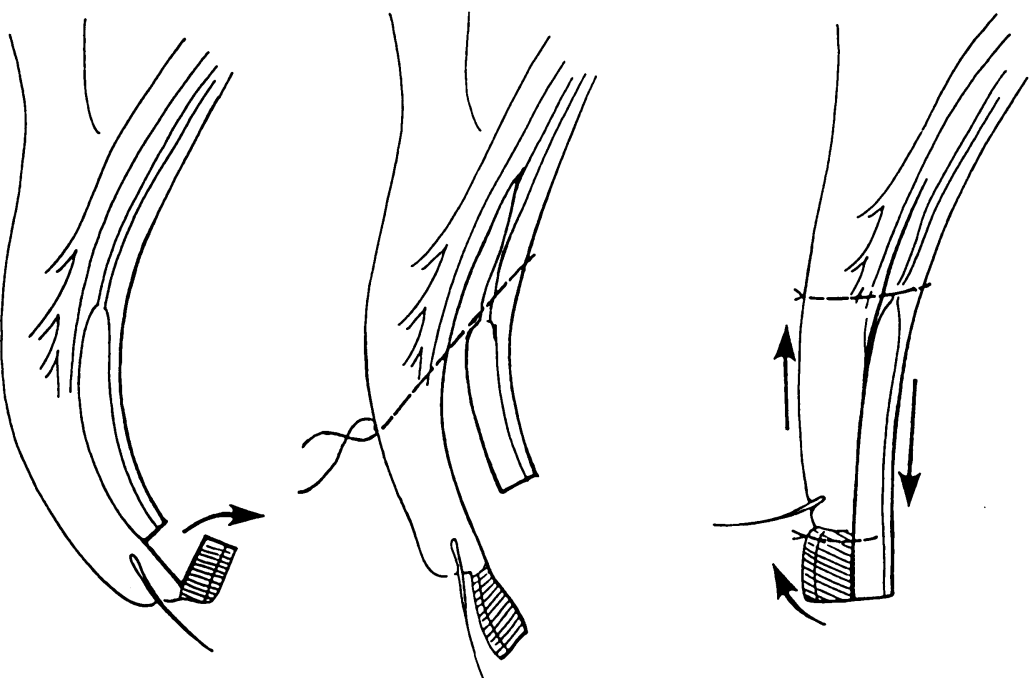

Figure 1B: Tarsal advance and rotation.

eversion splinting ${ }^{5}$; tarsal advance ${ }^{8}$; and tarsal grooving (Figs 1A-E). Lids with defective closure underwent tarsal advance. ${ }^{8}$

Surgery was performed with standard aseptic technique by one of three surgeons according to a standardised protocol under local anaesthesia with topical $4 \%$ and up to $3 \mathrm{ml}$ of $2 \%$ lignocaine with 1: 200000 adrenaline infiltrated into the neuromuscular plane. Sofratulle gauze and 5-0 silk were used for eversion splinting and 4-0 chromic catgut for the other operations. After operation the eyes were dressed with tetracycline $1 \%$ ointment instilled into the lower fornix and a pad.

Postoperative examination and dressings with further application of tetracycline $1 \%$ eye ointment were performed by ophthalmologists and by ophthalmic trained nurses either at the clinic or at the patient's home for six days. On the sixth day dressings were removed, and tetracycline $1 \%$ ointment was given to be applied twice daily to both eyes for six weeks to terminate active ocular chlamydia infection.' All patients were examined again by ophthalmic nurses 14 days postoperatively for eye lash/eye ball contact, and silk sutures and gauze rolls were
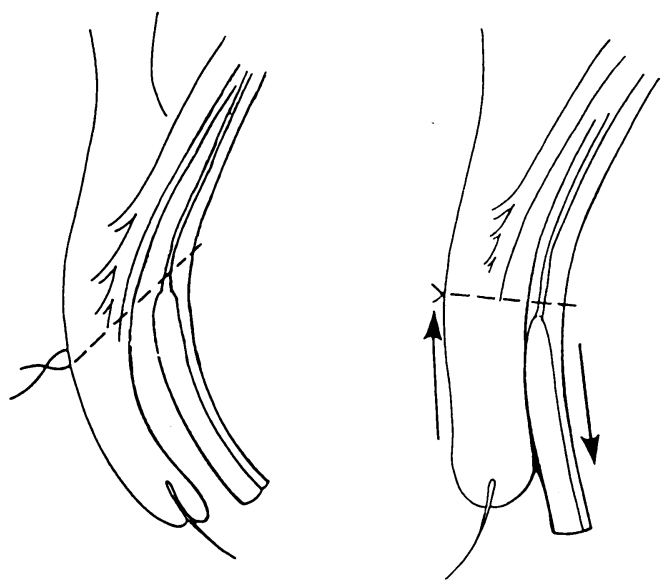

Figure 1D: Tarsal advance.

removed from lids that had undergone eversion splinting.

The primary measure of outcome was treatment success. This was defined as no eye lash/eye ball contact in the primary position of gaze and complete eye lid closure on asking the patient to close the eyes gently as in sleep.

Follow-up examination of all patients was performed with a $4 \times$ halogen illuminated loupe (Keeler) by MR either at clinics or at the patient's home. Information from proformas was entered into dBaseIII plus (Ashton-Tate) for analysis on microcomputer. The proportions of successful outcome at follow-up were compared by allocated operation and by operation done. Those lost to follow-up were included in the denominator. Crossovers of treatment after allocation occurred in five lids as follows. Three lids allocated to tarsal grooving were converted to bilamellar tarsal rotation, as there was insufficient tarsus for grooving: all had undergone previous surgery. One patient allocated tarsal advance became agitated at surgery, and eversion splinting was performed instead. One lid allocated to tarsal advance and rotation underwent tarsal advance in error. Eye lash/eye ball contact was present at 14 days postoperatively in one patient who had undergone eversion splinting, but in no others.

\section{Results}

One hundred and sixty five patients with major trichiasis and 32 with defective lid closure were enrolled consecutively between 1 January and 2 July 1986. A significant association between a history of previous surgery and defective lid closure was noted (Table I). The 165 lids with major trichiasis were allocated to one of five operations. Tarsal grooving had a smaller proportion of lids that had undergone previous surgery. Bilamellar tarsal rotation and tarsal grooving had a higher proportion of lids with trichiasis from half or more of the lid width. These differences were not significant overall (Table II). Losses to follow-up and duration of follow-up were comparable by allocation, but operative success was significantly different (Table III). This was also apparent after correcting for treatment crossovers (Table IV).

Bilamellar tarsal rotation was significantly more successful than eversion splinting 

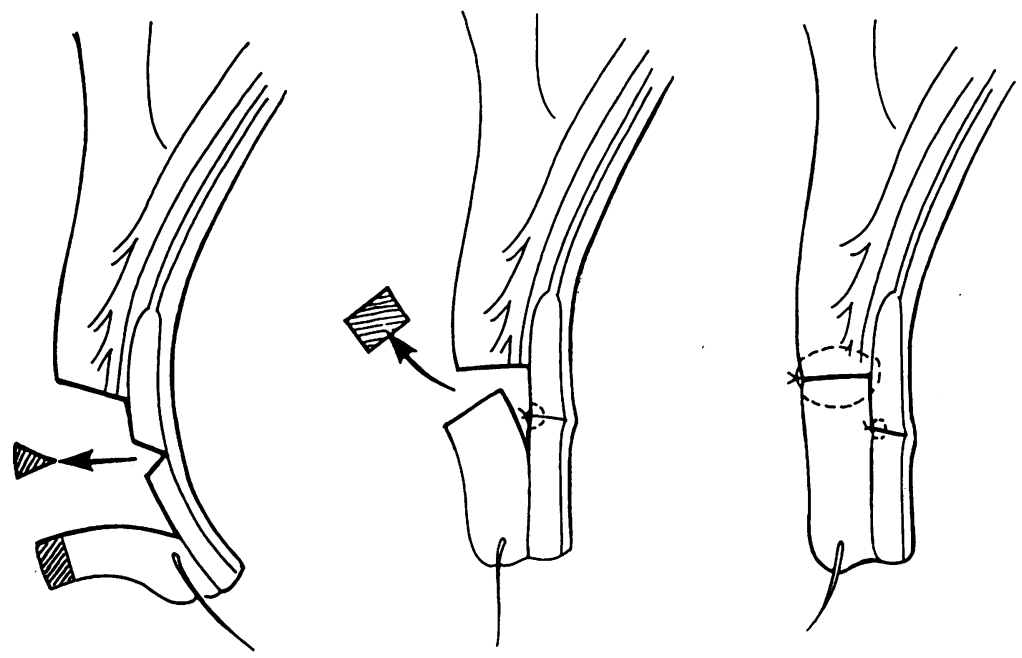

Figure 1E: Tarsal grooving.

TABLE I Lid closure and history of previous surgery in 197 trachomatous upper eyelids with major trichiasis and defective lid closure

\begin{tabular}{llll}
\hline & \multicolumn{3}{l}{ Lid closure defect } \\
\cline { 2 - 4 } & Yes & No & \\
\hline History of previous surgery: & 29 & 39 & 68 \\
Yes & 3 & 126 & 129 \\
No & 32 & 165 & 197 \\
Total & & \\
\hline
\end{tabular}

Odds ratio $=31,95 \% \mathrm{CI}(9,108)$

TABLE II Previous surgery and extent of major upper lid trichiasis by allocated operation

\begin{tabular}{lllllll}
\hline & $\begin{array}{l}\text { Bilamellar } \\
\text { tarsal } \\
\text { rotation }\end{array}$ & $\begin{array}{l}\text { Tarsal } \\
\text { advance } \\
\text { and rotation }\end{array}$ & $\begin{array}{l}\text { Eversion } \\
\text { splinting }\end{array}$ & $\begin{array}{l}\text { Tarsal } \\
\text { advance }\end{array}$ & $\begin{array}{l}\text { Tarsal } \\
\text { grooving }\end{array}$ & Total \\
\hline $\begin{array}{l}\text { Enrollment } \\
\text { Past surgery: }\end{array}$ & 41 & 24 & 24 & 41 & 35 & 165 \\
$\begin{array}{l}\text { No }(\%)^{\star} \\
\begin{array}{l}\text { Trichiasis } \geqslant 1 / 2 \text { lid width: } \\
\text { No }(\%) t\end{array}\end{array}$ & $12(29)$ & $8(33)$ & $5(21)$ & $11(27)$ & $3(9)$ & $39(24)$ \\
\hline
\end{tabular}

${ }^{\star} \chi^{2}=6 \cdot 7$, df $4, \mathrm{p}>0 \cdot 1$.

$+\chi^{2}=6 \cdot 9$, df $4, p>0 \cdot 1$.

TABLE III Follow-up and outcome of five operations for major upper lid trichiasis from trachoma by operation allocated

\begin{tabular}{|c|c|c|c|c|c|c|}
\hline & $\begin{array}{l}\text { Bilamellar } \\
\text { tarsal } \\
\text { rotation }\end{array}$ & $\begin{array}{l}\text { Tarsal } \\
\text { advance } \\
\text { and rotation }\end{array}$ & $\begin{array}{l}\text { Eversion } \\
\text { splinting }\end{array}$ & $\begin{array}{l}\text { Tarsal } \\
\text { advance }\end{array}$ & $\begin{array}{l}\text { Tarsal } \\
\text { grooving }\end{array}$ & Total \\
\hline $\begin{array}{l}\text { Enrollment } \\
\text { Lost to } \\
\text { follow-up: }\end{array}$ & 41 & 24 & 24 & 41 & 35 & 165 \\
\hline $\begin{array}{l}\text { No (\%) } \\
\text { Mean time of }\end{array}$ & $2(5)$ & $2(8)$ & $3(12)$ & $3(7)$ & $2(6)$ & $12(7)$ \\
\hline $\begin{array}{l}\text { Months } \\
\text { Range }\end{array}$ & $\begin{array}{l}7 \cdot 4 \\
5-10\end{array}$ & $\begin{array}{l}8 \cdot 8 \\
8-10\end{array}$ & $\begin{array}{l}8 \cdot 7 \\
5-11\end{array}$ & $\begin{array}{l}7 \cdot 5 \\
5-10\end{array}$ & $\begin{array}{l}7 \cdot 7 \\
5-10\end{array}$ & $\begin{array}{l}7 \cdot 9 \\
5-11\end{array}$ \\
\hline $\begin{array}{l}\text { Success: } \\
\text { No }(\%)^{\star}\end{array}$ & $29(71)$ & $11(46)$ & $7(29)$ & $11(27)$ & $4(11)$ & $62(38)$ \\
\hline
\end{tabular}

${ }^{\star} \chi^{2}=32 \cdot 8$, df $4, \mathrm{p}<0 \cdot 001$.

TABLE IV Crossovers from allocated operations and outcome by operation done

\begin{tabular}{lllllll}
\hline & $\begin{array}{l}\text { Bilamellar } \\
\text { tarsal } \\
\text { rotation }\end{array}$ & $\begin{array}{l}\text { Tarsal } \\
\text { advance } \\
\text { and rotation }\end{array}$ & $\begin{array}{l}\text { Eversion } \\
\text { splinting }\end{array}$ & $\begin{array}{l}\text { Tarsal } \\
\text { advance }\end{array}$ & $\begin{array}{l}\text { Tarsal } \\
\text { grooving }\end{array}$ & Total \\
\hline Enrollment & 41 & 24 & 24 & 41 & 35 & 165 \\
Crossovers from: & 0 & 1 & 0 & 1 & 3 & 5 \\
$\quad$ to: & 3 & 0 & 1 & 1 & 0 & 5 \\
Final numbers & 44 & 23 & 25 & 41 & 32 & 165 \\
Success $(\%)^{\star}$ & $30(68)$ & $10(43)$ & $8(32)$ & $11(27)$ & $3(9)$ & $62(38)$ \\
\hline
\end{tabular}

${ }^{\star} \chi^{2}=31 \cdot 1$, df $4, p<0 \cdot 001$. $\left(\chi^{2}=7.035, \mathrm{p}<0.01\right) ;$ tarsal advance $\left(\chi^{2}=12.38\right.$ $\mathrm{p}<0.001)$, and tarsal grooving $\left(\chi^{2}=23 \cdot 74\right.$, $\mathrm{p}<0.001)$, but not significantly more successful than tarsal advance and rotation $\left(\chi^{2}=2 \cdot 87\right.$, p $>0.05$ ) (Fig 2). Bilamellar tarsal rotation was the most successful operation regardless of previous surgery, extent of trichiasis preoperatively, and surgeon (Table V).

First operations and lids with trichiasis from less than half the lid margin had higher rates of success, with the exception of eversion splinting and previous surgery (Table V). Failures were least severe for bilamellar tarsal rotation and tarsal advance and rotation, most lids having five or fewer lashes at follow-up, whereas major trichiasis recurred in a large proportion of lids that underwent the remaining three operations (Table VI). Defective lid closure developed only after bilamellar tarsal rotation and tarsal grooving (Table VI).

Of 32 lids with defective lid closure at enrollment $26(81 \%)$ were followed up between four and 10 (mean 7) months after tarsal advance. Two (6\%) were successfully treated. Nine $(28 \%)$ had relief of eye lash/eye ball contact, and 10 (31\%) had lid closure restored.

\section{Discussion}

The present study is the first to report a randomised trial of eye lid surgery for tachomatous trichiasis. A simple preoperative grading scheme and postoperative criterion of treatment success were used, the grades depending on the number of lashes making contact with the eye ball and gentle lid closure. This is in accord with the current World Health Organisation system for the assessment of trachoma and its complications, in which trichiasis is defined as the presence of any eye lash/eye ball contact regardless of entropion ${ }^{10}$ and on recognition of the importance of defective lid closure." Our minor trichiasis grade was defined by five or fewer lashes, as we had found this to be the number readily treated with electroloysis. The major grade was subdivided by the extent of trichiasis, if localised to less than half, or involving half or more of the lid margin. This subdivision has been previously described.

The operative groups were comparable for factors likely to influence outcome, previous surgery, extent of trichiasis, and follow-up. Enrollment was unequal, as may be expected with randomised allocation in which a blocking procedure is not used. ${ }^{12}$

The outcome with lids grouped by operation allocated and by operation done was similar, as crossovers from allocated operations were few (Tables III and IV). Bilamellar tarsal rotation and tarsal advance and rotation were the most successful operations. The pattern of successful outcomes for all operations was similar after stratification by factors likely to influence outcome - namely, previous surgery, extent of preoperative trichiasis, and surgeon (Table V). The same pattern was observed when operative failure is considered in which the more successful operations had less severe failures (Table VI). The difference of success rate between surgeons was less marked than Table $\mathrm{V}$ would suggest: 


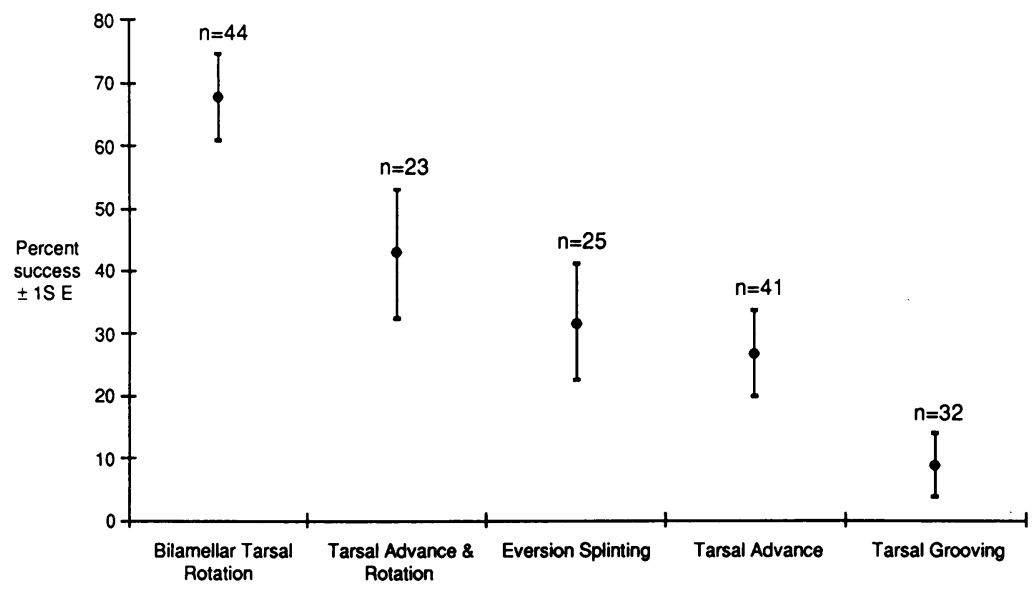

Figure 2: Proportion of successful results for five operations for upper lid trichiasis from trachoma.

firstly because failures for bilamellar tarsal rotation and tarsal advance and rotation mainly comprised only one or two lashes at the lateral canthus; and, secondly, because a higher proportion $(50 \%)$ of lids undergoing bilamellar tarsal rotation by surgeon 2 had undergone previous surgery.

We encountered no serious side effects with any of the operations, but two minor complications were seen with bilamellar tarsal rotation - overcorrection and granuloma formation. One lid was overcorrected, with the

TABLE V Outcome of five operations for major upper lid trichiasis stratified by previous surgery, extent of trichiasis, and surgeon

\begin{tabular}{|c|c|c|c|c|c|c|}
\hline & \multicolumn{6}{|l|}{ Operation } \\
\hline & $\begin{array}{l}\text { Bilamellar } \\
\text { tarsal } \\
\text { rotation }\end{array}$ & $\begin{array}{l}\text { Tarsal } \\
\text { advance } \\
\text { and rotation }\end{array}$ & $\begin{array}{l}\text { Eversion } \\
\text { splinting }\end{array}$ & $\begin{array}{l}\text { Taral } \\
\text { advance }\end{array}$ & $\begin{array}{l}\text { Tarsal } \\
\text { grooving }\end{array}$ & Total \\
\hline \multicolumn{7}{|l|}{ Previous surgery } \\
\hline Number & & & & & & \\
\hline Success (\%) & $23(72)$ & $7(47)$ & $6(30)$ & $9(30)$ & $3(10)$ & $48(38)$ \\
\hline & & & & 11 & & 39 \\
\hline Success (\%) & $7(58)$ & $3(37)$ & $2(40)$ & $2(18)$ & $0(0)$ & $14(36)$ \\
\hline \multicolumn{7}{|c|}{ Trichiasis $<o r \geqslant 1 / 2$ lid width } \\
\hline$<1 / 2$ & & 12 & 11 & 18 & & \\
\hline Success $(\%)$ & $10(77)$ & $7(58)$ & $6(54)$ & $5(28)$ & $2(25)$ & $30(48)$ \\
\hline$\geqslant 1 / 2$ & 31 & 11 & 14 & 23 & 24 & 103 \\
\hline Success (\%) & $20(64)$ & $3(27)$ & $2(14)$ & $6(26)$ & $1(4)$ & $32(31)$ \\
\hline \multirow{2}{*}{\multicolumn{7}{|c|}{$\begin{array}{l}\text { Surgeon } \\
\text { Surgeon } 1\end{array}$}} \\
\hline & & & & & & \\
\hline Number & 31 & 11 & 16 & 31 & 21 & 110 \\
\hline Success $(\%)$ & $20(64)$ & $4(36)$ & $6(37)$ & $7(23)$ & $2(9)$ & $39(35)$ \\
\hline \multicolumn{7}{|l|}{ Surgeon 2} \\
\hline Number & & & & & & 37 \\
\hline Success (\%) & $3(50)$ & $2(29)$ & $1(17)$ & $3(33)$ & $1(11)$ & $10(27)$ \\
\hline \multicolumn{7}{|l|}{ Surgeon 3} \\
\hline Number & 7 & 5 & & & 2 & 18 \\
\hline Success (\%) & $7(100)$ & $4(80)$ & $1(33)$ & $1(100)$ & $0(0)$ & $13(72)$ \\
\hline \multicolumn{7}{|l|}{ Overall number } \\
\hline Number & 44 & 23 & 25 & 41 & 32 & 165 \\
\hline Success $(\%)$ & $30(68)$ & $10(43)$ & $8(32)$ & $11(27)$ & $3(9)$ & $62(38)$ \\
\hline
\end{tabular}

TABLE VI Recurrent trichiasis and defective lid closure at follow-up after five operations for major upper lid trichiasis from trachoma

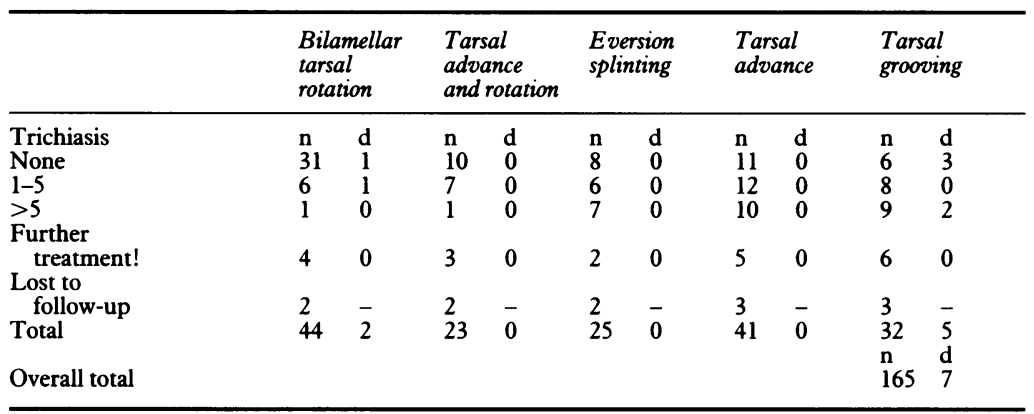

$\mathrm{n}=$ Number of lids.

$\mathrm{d}=$ Of which $\mathrm{d}$ lids had defective lid closure.

!= Epilation (17 lids) or surgery ( 3 lids) prior to follow up. distal fragment being rotated $180^{\circ}$ back on to the proximal part of the lid. The wound was reopened and resutured with less tension four days after the initial procedure. Overcorrection after bilamellar tarsal rotation is caused by excessive tension of eversion sutures or a too large marginal fragment. ${ }^{13}$ Two lids developed granulomas at the tarsal incision, which did not recur after excision. Ischaemic necrosis of the marginal fragment has been suggested as a possible complication of bilamellar tarsal rotation but was not observed. ${ }^{14}$ The effectiveness of bilamellar tarsal rotation in our series accords with a high $(96 \cdot 7 \%)$ success rate reported for a similar tarsal rotation operation. ${ }^{15}$

Our $32 \%$ success rate for eversion splinting with a gauze roll compares poorly with $98.5 \%$ originally reported for this operation and might be due to racial and environmental differences between Burma and Oman or to high losses to follow-up in the original report. ${ }^{5}$ Inquiry revealed that tarsal grooving had been the most widely performed operation for upper lid trichiasis in Oman. The association between previous surgery and defective lid closure (Table I) could not be taken as proof as a casual relationship between tarsal grooving and defective lid closure, which could be explained at least in part by a primary association between past surgery and severe cicatrising disease. However, at postoperative follow-up $16 \%$ of eyes developed defective lid closure after tarsal grooving compared with $5 \%$ for bilamellar tarsal rotation and none for the remaining three procedures (Table VI), which does suggest that tarsal grooving may result in defective lid closure. This is plausible, as tarsal grooving was the only operation requiring excision of tissue.

A disparity in the effectiveness of upper lid entropion operations advocated for community based lid surgery' has been demonstrated. Bilamellar tarsal rotation and tarsal advance and rotation at short term follow-up are reasonably effective, but eversion splinting, tarsal advance, and tarsal grooving were ineffective. Tarsal advance was also ineffective for defective lid closure.

Operations appropriate for community use should be able to be performed effectively and swiftly by non-specialist medical or paramedical staff with minimal resources. Bilamellar tarsal rotation was found to be simpler and quicker than tarsal advance and rotation. Trachomatous cicatrisation may be progressive in many patients, so that recurent trichiasis may be expected with time in an increasing proportion of lids even after effective surgery. Longer follow up of appropriate operations is therefore still required to evaluate the place of community based trichiasis surgery as a strategy for prevention of blindness from trachoma.

We thank the following for their help: His Excellency Dr Ali bin Mohamed bin Moosa, His Excellency Dr Mubarak Al-Khoudouri, Professor S Darougar, Mr Khalfan Nasser, Mr S Brogan, Dr H R Taylor, Dr S West, Mrs B Munoz, and the staff of the National Taylor, Dr S West, Mrs B Munoz, and the staft
Health Programme, Ministry of Health, Oman.

1 Dawson CR, Jones BR, Tarizzo ML. Guide to trachoma control Geneva: World Health Organisation, 1981.

2 World Health Organisation. Strategies for the prevention of blindness in national programmes. Geneva: World Health Organisation, 1984. 
3 Collin JR, Jones BR. Upper lid entropion. In: The cornea in health and disease. VIth Congress of the European Society of
Ophthamology. Royal Society of Medicine International Ophthamology. Royal Society of Medicine In

$4 \mathrm{Kemp}$ EG, Collin JRO. Surgical management of upper lid entropion. Brf Ophthalmol 1986; 70: 575-9.

5 Nyunt $W$ in W. Surgery for trachoma in Burma. $\mathrm{Br} f$ Ophthalmol 1976; 63: 113-6.

6 Darougar S. Assignment report: control and prevention of blindness in Oman. WHO: EM/PBL/15. EM/ophthal/21. $E M / O m a / P B L / 001.1982$.

7 Ballen P. A simple procedure for the relief of trichiasis and entropion of the upper lid. Arch Ophthalmol 1964; 72: 23940.

8 Collin JRO. A manual of systematic eyelid surgery. London: Churchill-Livingstone, 1983: 16-22.
9 Fox S. Ophthalmic plastic surgery. 5th ed. New York; Grune

10 Thylefors B, Dawson CR, Jones BR, West SK, Taylor HR. A simple system for the assessment of trachoma and its
complications. Bull WHO 1987;65:477-83.

11 Jones BR, Barras TC, Hunter PA, Daraougar S. Neglected lid deformities causing progressive corneal disease. Trans Ophthalmol Soc UK 1976; 96: 45-51.

12 Meinert CL. Clinical trials; design, conduct and analysis. Oxford: Oxford University Press, 1986.

13 Bayliss HI, Cies WA, Kamin DF. Overcorrections of the Wies procedure. Trans Ophthalmol Soc UK 1976; 96: 458-61.

14 Soll D, ed. Management of complications in ophthalmic plastic surgery. Birmingham, Alabama: Aesculapius, 1976: 156.

15 Halasa A, Jarudi N. Tarsotomy for the correction of cicatricial entropion. Arch Ophthalmol 1974; 6: 837-40. 